\title{
Medbesedilni vidik Jančarjevih romanov Drevo brez imena in To noč sem jo videl
}

\author{
Martina Potisk \\ martina.potisk@gmail.com
}

SCN V/2 [2012], 82-93

\begin{abstract}
Prispevek obravnava izbrane medbesedilne prvine v romanih Draga Jančarja Drevo brez imena (2008) in To noč sem jo videl (2010), pri čemer se podrobneje osredotoča na funkcijo mota, pomen navezovanja na ljudsko slovstvo, literarne reference, izražene skozi montažo in izposojo ter vključenost metričnega citata $\mathrm{v}$ romaneskno sobesedilo. Posebna pozornost je namenjena delom predlog, na katere se navezujejo medbesedilni sklici, in njihovi vlogi pri soustvarjanju celovite podobe osrednjih likov ter vzpostavljanju idejno-tematske zasnove romana.
\end{abstract}

The paper deals with selected intertextual elements in the novels by Drago Jančar Drevo brez imena (The Nameless Tree, 2008) and To noč sem jo videl (I Saw Her That Night, 2010), thereby specifically focuses on the function of the motto, the signification of the reliance on folk literature, literary references, expressed by the montage and borrowing, and the inclusion of the metric quote in the textual context. Special attention is given to the parts of templates, to which intertextual references are related, and their role in creating a comprehensive image of the main characters and contributing to the ideaed-thematic base of the novels.

Ključne besede: sodobni slovenski roman, Drago Jančar, Drevo brez imena, To noč sem jo videl, medbesedilnost, analiza

Key words: contemporary Slovenian novel, Drago Jančar, The Nameless Tree, I Saw Her That Night, intertextuality, analysis

\section{Jančarjev romaneskni opus}

Prozni opus Draga Jančarja obsega devet romanov; roman Petintrideset stopinj (1974) je še v znamenju visokega modernizma, mestoma reizma, v Galjotu (1978) se prepletata raba modernistične pripovedne tehnike in duhovno-te- 
matsko sledenje eksistencialistični literaturi. Severni sij (1984) predstavlja že očitnejši premik v postmodernistično poetiko, zlasti glede na slogovno-formalne (postmodernistične) postopke, ki so nedvomno najbolj očitni v Posmehljivem poželenju (1993) (Kos 2001: 397-399). Za preostale Jančarjeve romane (Zvenenje v glavi, 1998; Katarina, pav in jezuit, 2000; Graditelj, 2006; Drevo brez imena, 2008; To noč sem jo videl, 2010) pa je še posebej značilen izrazito razgiban literarnosmerni sinkretizem, čeprav se sicer zdi, da so še najbližje neorealizmu.

Kljub omenjenim literarnosmernim navezavam pa duhovnozgodovinska analiza Jančarjevih romanov kaže, da se ti še najmočneje navezujejo na eksistencializem in posteksistencializem (Virk 2000: 202), kajti pri Jančarju subjektova usoda nikoli ni neomejena, temveč je skoraj vedno naddeterminirana z zgodovino, s transcendentno ali z imanentno usodo (Virk 1997: 88). Opaznejše mesto $\mathrm{v}$ pisateljevih romanih tako zavzema problematika disidentstva in izobčenstva; izobčenstvo likov determinira usoda, ob njej pa prične stopati v ospredje problematika zgodovine, ki neustavljivo kroji njihovo življenje in delovanje (prav tam: 68).

$\mathrm{V}$ to tematsko paradigmo lahko uvrstimo tudi romana Drevo brez imena (2008) in To noč sem jo videl (2010). Prvi prinaša zgodbo arhivarja Janeza Lipnika, ki mu branje zapiskov o ljubezenskih dogodivščinah »Velikega Ljubimca« predstavlja svojevrsten beg iz sedanjosti, zato pričenja počasi izgubljati razsodnost in tako postopoma postane žrtev svojih lastnih iluzij in spominov. »Zgodovina«, ki skozi arhivska poročila usodno vpliva na Lipnikovo življenje, odigra pomembno vlogo tudi v romanu To noč sem jo videl, kjer postane glavna protagonistka Veronika Zarnik zaradi spleta čudnih naključij, osebnih nagibov in krive ovadbe tragična žrtev razburkanega časa na Slovenskem med drugo svetovno vojno.

\section{Medbesedilne navezave $v$ Jančarjevih romanih}

Samostojnih razprav o medbesedilni pestrosti Jančarjevih romanov skorajda ni; te so povečini vključene $\mathrm{v}$ znanstvene monografije literarnih preučevalcev (F. Zadravec, H. Glušič, J. Kos, T. Virk, S. Borovnik idr.) ali pa so del diplomskih nalog, kjer so ponavadi obravnavane v povezavi z drugimi značilnostmi Jančarjevih del. Na tem mestu naj izpostavim celovite raziskave o literarizaciji slovstvene folklore v romanih Draga Jančarja, o čemer pričata prispevek Marije Stanonik Funkcija slovstvene folklore v sodobnem slovenskem romanu (2003) in obsežna razprava Marjetke Golež Kaučič Ljudsko pesemsko izročilo kot kulturni spomin Jančarjevega romana in drame Katarina, pav in jezuit (2007).

Sama sem medbesedilno sklicevanje v Jančarjevih romanih obravnavala $\mathrm{v}$ svoji diplomski nalogi z naslovom Medbesedilnost $v$ romanih Draga Jančarja (2011), kjer sem ugotavljala zastopanost posameznega medbesedilnega sklica v pisateljevem romanesknem opusu. Izhajajoč iz Juvanove teorije medbesedilnih 
figur in zvrsti sem opredelila opažene medbesedilne navezave in jih razvrstila glede na predloge. Izkazalo se je, da v Jančarjevih romanih prevladujejo citati, pregovori oziroma rekla, toposi in aluzije $\mathrm{v}$ povezavi z drugimi navezavami, tem sledijo montaže in izposoje. Medbesedilno najbogatejši so romani Katarina, pav in jezuit (2000), Posmehljivo poželenje (1993) in Graditelj (2006), najmanj intertekstualnih referenc pa vsebujeta romana To noč sem jo videl (2010) in Petintrideset stopinj (1974).

Medbesedilna analiza romana Drevo brez imena (2008) je pokazala, da poleg številnih in raznovrstnih citatov v njem prevladujejo še inovativni primeri montaže, kakršnih ni v nobenem drugem Jančarjevem romanu. Podobna izvirnost velja tudi za roman To noč sem jo videl (2010), ki je sicer glede na število medbesedilnih navezav dokaj šibko delo, vendar pa zajema izvirne in mojstrsko vključene prvine slovstvene folklore, zlasti ljudskega pesništva. V pričujočem prispevku želim prikazati medbesedilne podobnosti in razlike med obema romanoma ter njihovo vlogo pri vzpostavljanju njune idejno-tematske zasnove. Pri tem se bom osredotočila na pomen mota, citate ljudskega slovstva, montažo in izposojo ter vlogo (metričnega) citata; obenem bom pojasnila njihov doprinos $\mathrm{k}$ utrditvi (post)eksistencialistične duhovnozgodovinske podlage omenjenih romanov.

\subsection{Moto v romanih Drevo brez imena in To noč sem jo videl}

Izmed vseh romanov Draga Jančarja se le romana Drevo brez imena in To noč sem jo videl pričenjata z motom, ki je ponavadi kot navedek postavljen za naslov in pred začetek celotnega besedila. Moto ima dve funkciji: komentarsko in/ali napovedno, ki bralcu napove temo in opozarja na izbrano pomensko razsežnost besedila, ter »usmerjevalno«, ki bralcu nakaže, na katerem ozadju naj sprejema pomen dela (Juvan 2000: 29).

$\mathrm{V}$ obeh Jančarjevih romanih moto kot medbesedilna figura prenosa jezikovnega izraza v skladu s svojo komentarsko/napovedno funkcijo bralcu približa idejno-tematsko polje, v okviru katerega mora romana dojemati. Navedek Koheleta v Drevesu brez imena opozarja na človekovo vpetost v ponavljajoče se, ciklično zgodovinsko dogajanje. V romanu se tako izkaže, da dogodki iz preteklosti pronicajo skozi arhivske dokumente v življenje glavnega lika, povzročijo njegovo zmedenost in duševno nestabilnost. Zgodovina se torej $\mathrm{v}$ vlogi usode s posameznikom poigrava in ga skoraj povsem posrka vase, usodna, mestoma celo omejevalna sila zgodovine pa je s tem postavljena nad človeka. Sorodna tematika velja tudi za roman To noč sem jo videl, katerega moto [»...naše izmišljene zgodbe, narejene iz resničnosti ... $H$. C. Andersen (Jančar 2010: 5)] opozarja na verodostojno, potencialno možno dogajanje, ki vseskozi poteka v realnih zgodovinskih okoliščinah, pri čemer se dotika nič hudega slutečih fiktivnih oseb, ki nazadnje postanejo nesmiselne žrtve druge svetovne vojne. Komentarska vloga obeh motov je pravzaprav tesno povezano z njuno usmerjevalno funkcijo, ki kaže na tematsko sorodnost romanov; oba 
namreč izhajata iz pojmovanja zgodovine kot spleta naključij, neprizanesljive usode, ki nenehno bdi nad posameznikom in vpliva na njegovo življenje.

\subsection{Prvine slovstvene folklore v romanih Drevo brez imena in To noč sem jo videl}

Izmed obeh obravnavanih romanov je z vidika medbesedilnih navezav na ljudsko slovstvo bogatejši roman To noč sem jo videl, ki večinoma zajema prvine ljudskega pesništva. Po mnenju Marjetke Golež Kaučič je tovrstno slovstvo nosilec identitete naroda, njegovi produkti pa spadajo med kanonska besedila, saj se z nenehnim ponavljanjem in transformiranjem pomenov - tudi prek medbesedilnih pojavov - skozi različne spominske procese vračajo v kulturni oziroma literarni obtok. Ljudska pesem je kot motivna in tematska odnosnica velikokrat (duhovna) podlaga pesniškim in proznim delom. Obenem so elementi ljudske pesmi kot del kolektivnega spomina pogosto uporabljeni za hiter in neposreden prenos avtorjevih idej in sporočil sodobnemu bralcu (Golež Kaučič 2007: 77-81).

$\mathrm{V}$ romanu To noč sem jo videl je ljudska pesem rabljena kot sredstvo za karakterizacijo likov, zlasti osrednje protagonistke. Zdi se, da bi moral bralec pri dojemanju literarnih oseb upoštevati tovrstne medbesedilne sklice že zato, ker se ljudska pesem največkrat pojavlja kot nekakšna asociacija, spomin na Veroniko, ki je vpleten med pripovedovanje drugih literarnih oseb. O Veroniki namreč spregovorijo: Stevan, Veronikin nekdanji ljubimec in oficir jugoslovanske kraljeve vojske, njena mati, zdravnik nemške okupacijske vojske, gospodinja in delavec na posestvu, ki je bil posredno kriv za njen tragični konec.

Medbesedilne navezave, zlasti dobesedni in pretvorjeni citati ljudskih pesmi, Veroniko izrisujejo kot zelo priljudno, skorajda že »ljudsko« osebo, ki pa se je pogosto polasti nekakšna otožnost, ki mestoma spominja na »lepovidinsko« hrepenenje po osebni svobodi in ljubezenski sreči. To je izraženo tudi z večkrat ponovljenim citatom pesmi Nocoj pa, oh, nocoj, vpetim med pripovedovanja oficirja in Veronikinega nekdanjega ljubimca Stevana:

I... c čez dolgih sedem let se bova vidla spet, je pela tisto slovensko narodno pesem, $\mathrm{ki}$ jo je imela posebej rada, kadar je bila otožna in je gledala s tistim odsotnim pogledom, s kakršnim me je gledala tudi zdaj, sam Bog nebeški ve, kdaj sedem let bo preč. (Jančar 2010: 8)

Na nedoseženo Veronikino ljubezensko srečo namigujejo tudi citatno vključene ljubezenske lirske pesmi drugih narodov, kakršna je naslednja:

I.../ vsi skupaj smo potem na neki svatbi dolgo v noč prepevali Oj Moravo ... Ciganski trobentači so strnili krog okrog našega omizja in nam igrali vranjanske pesmi, ena se je Veroniki posebej vtisnila v dušo: otvori mi belo Lenče, vratanca, vratanca ... takšna lepa pesem, je rekla ... da ti vidim, belo Lenče, ustanca, ustanca /.../ (Jančar 2010: 42) 
Tovrstne pesmi v medbesedilni kombinaciji z elementi slovenske slovstvene folklore bralca opominjajo na nepremostljivo razliko med Veroniko in Stevanom; dejstvo, da je bila Veronika poročena, in njegova vojaška služba sta $\mathrm{v}$ primerjavi z njuno različno narodno pripadnostjo predstavljala bistveno večji problem.

Veronikina otožnost in žalost postaneta na trenutke tako opazni, da ju Stevan ne more spregledati; temu nameni več kratkih opazk, marsikatera izmed njih vsebuje medbesedilni sklic. Kombinacijo medbesedilnih figur opisa jezikovnega izraza, tj. metafikcijske digresije in opombe, zajema tudi naslednje oficirjevo predvidevanje:

Na dan, ko sem prestal svojo kazen, sem jo našel v solzah. Mislil sem, da jo je zajel »dert«, dert je tisto otožno občutje iz one spevoigre o Koštani, hrepenenje zaprte ženske po življenju. (Jančar 2010: 45)

Prenašanje ljudskega slovstva iz roda v rod je močno povezano z medgeneracijsko naklonjenostjo in ljubeznijo do folklornega izročila. Veronikina mati tekom pripovedovanja pričakuje vrnitev svoje hčere, odvedene na ukaz partizanov, in se spominja njenih mladostnih dni, pa tudi svojih veselih trenutkov $\mathrm{z}$ možem Petrom. Med njene spomine se prikradejo citati italijanske narodne pesmi La mula de Parenzo (»Tutti mi chiamano bionda, ma bionda io non sono /.../« Jančar 2010: 78-79), o kateri je svojčas pripovedovala Veroniki, kar je še en dokaz za izrazito »ljudskost« osrednje protagonistke.

Jančar je z rabo medbesedilnih sklicev na ljudske pesmi glavno osebo Veroniko prikazal kot dokaj preprosto in prijetno žensko. Prav vključenost številnih folklornih elementov jo namreč zelo približa bralcu, zaradi česar se ga njena tragična usoda toliko bolj dotakne in pretrese. $Z$ rabo medbesedilnih prvin je namreč pisatelj dogodke, povezane z Veroniko in njeno družino, uporabil kot središče tematsko-idejne podlage romana in kot nekakšen prototip za nič koliko slovenskih družin med drugo svetovno vojno, ki jih je po krivem prizadela nesmiselna morija.

V nasprotju z romanom To noč sem jo videl, kjer prevladujejo citati ljudskega pesništva, pa se celoten roman Drevo brez imena opira in se preko številnih medbesedilnih navezav oziroma asociacij vrača $\mathrm{k}$ folklornemu proznemu žanru, tj. čudežni »pohorski« pravljici z naslovom $N a$ drevesu brez imena, ki jo je Lipniku v otroških letih brala mati in je v roman vstavljena v obliki obsežnega, več strani obsegajočega dobesednega citata:

Bilo je čuda visoko drevo, kakršnega svet še ni videl in ga tudi ne bo. Dvigalo se je proti nebu kakor dim goreče zemlje, da si videl samo deblo in samo sonce, listja in vej pa ne. Ljudje bi radi dali velikanu ime, če bi vedeli, kakšne veje in liste ima. Mnogo let so iskali junaka, ki bi si upal splezati do prve veje. vse je bilo zaman, našli ga niso. Nekega dne se je pri njih oglasil preprost človek, pastir. Prišel je iz daljnih južnih krajev in obljubil, da jim izpolni dolgoletno željo. Zahteval je dobro plačilo, če delo dovrši, prej pa še: tri sekire, vrv, ki bo segala do najvišje gore, in orla, ki bi mu prinašal hrano /.../ (Jančar 2008: 214) 
Lipnikovo plezanje po drevesu se je tako začelo že v otroških letih in se pravzaprav ni nikoli končalo:

Vseeno, grěs navzgor ali greš navzdol, tam te čaka drug svet. Že ko je bil majhen deček, je to vedel. Takrat se je pokril z odejo čez glavo, poslušal je moške glasove iz kuhinje, ki so se zmeraj bolj oddaljevali, kajti on je odhajal, z veliko lahkoto je plezal po drevesu, s katerega je bilo tam nekje visoko zgoraj mogoče sestopiti nekam drugam, $v$ neko drugo pokrajino.

Plezam po drevesu, z veliko lahkoto se vzpenjam po drevesu, za katero ne vem, ali je jelka ali je smreka, ali javor ali hrast, pravzaprav nič od tega, ampak nekaj povsem drugega. (Jančar 2008: 8)

»Plezanje po drevesu« je torej metafora za pobeg iz realnosti in predstavlja nekakšen Lipnikov »izhod v sili«; ko se problemi, negotovosti in zakonske težave osrednjega protagonista preveč nakopičijo, se ta mrzlično zateče k arhivskim zapiskom neznanega erotomana, med katere primeša še svoje neizživete sanje in fantazije, otroško »ljubezen« do učiteljice Zale in drobce vojaških zgodb svojega bolnega očeta.

Lipnikove prehode med resničnim svetom in vizijami iz njegovih sanjarjenj vzpostavljajo tudi številne aluzije, ki pronicajo skozi citate Prešernovega Sonetnega venca in Turjaške Rozamunde ter Aškerčeve Ponočne potnice. Najobsežnejša medbesedilna navezava, dobesedni citat ljudske čudežne pravljice $\mathrm{Na}$ drevesu brez imena, ki prikazuje Lipnikovo bolestno navezanost na čas otroštva, pa se v romanu večkrat ponovi tudi v skrajšani, pretvorjeni, variirani in/ali parafrazirani obliki. T. i. »plezanje na drevo«, ki služi kot preneseno pojmovanje za Lipnikove pobege v domišljijo, najbrž ne temelji zgolj na omenjeni pravljici; med pripovedovanje se namreč - morda tudi nehote - vrivata motivno-tematska reminiscenca in aluzija na pesem Edvarda Kocbeka Deček na drevesu kot literarno referenco, ki v določenih segmentih prav tako izraža eksistencialno problematiko iskanja smisla, negotovosti in nasprotij med navideznim in resničnim, izvirajočih iz idealiziranih spominov na otroštvo.

V Drevesu brez imena večina medbesedilnih navezav, ki se pojavljajo tako v Lipnikovem »sanjskem« kot resničnem svetu, bralca opozarja na dvodimenzionalnost njegovega življenja. Če se v romanu To noč sem jo videl medbesedilne prvine pojavljajo kot sredstvo, s katerim želi pisec bralcu približati in označiti osrednjo protagonistko, so v Drevesu brez imena tovrstni sklici prisotni zlasti z namenom krepitve (post)eksistencialistične duhovnozgodovinske podlage in idejno-tematske zasnove romana. Ob tem naj dodam, da je obema romanoma skupno medbesedilno posredovanje zunajbesedilnih prostorov; dogajanje se namreč odvija na realnem zgodovinskem ozadju druge svetovne vojne, le da so v romanu To noč sem jo videl osrednje osebe njegove neposredne žrtve, v Drevesu brez imena pa pogubna moč vojne/zgodovine na Lipnika deluje posredno - deli slišanih zgodb in prebranih arhivskih dokumentov, ga tako miselno obsedejo, da prične biti sam svojo bitko, bitko med realnostjo/budnostjo in sanjami. 


\subsection{Literarne reference, ki pronicajo skozi montažo in izposojo}

Montaža je citatna zvrst prenosa jezikovnega izraza in besedilnega sveta, ki omogoča združevanje različnih ravni resničnosti in s tem razdira slogovno ubranost besedila. Navezuje se lahko na raznovrstne predloge, zajete ne samo iz literature, ampak tudi iz publicistike, oglasov itd. (Juvan 2000: 268). Kljub temu da je bila montaža prvotno nekoliko bolj značilna za pesniška besedila, jo lahko opazimo v Jančarjevih romanih, kjer se pogosto pojavlja kot sredstvo za vključevanje »literature v literaturo«, s čimer nedvomno potrjuje svojo medbesedilno vlogo. Po številu montaž med Jančarjevi romani izrazito izstopa roman Drevo brez imena, ki tudi na takšen, medbesedilno-vizualni način opozarja bralca na Lipnikovo potovanje med dvema vzporednima, zanj seveda enakovrednima, svetovoma.

$\mathrm{V}$ romanu se poleg fotografij in angleških sestavkov, v katere se potaplja Lipnik, pojavljajo tudi številne aluzije na »plezanje po drevesu«. Vsaka, še tako majhna - včasih popolnoma nesmiselna in tragikomična - podrobnost, ki v Lipniku vzbudi asociacijo na znano pohorsko pravljico, ga namreč skoraj docela pretrese in vznemiri. Takšen učinek v njem vzbudi tudi jed iz kitajske restavracije z imenom »mravlje plezajo na drevo«, kar je v romanu prav zaradi montaže fotokopiranega dela jedilnega lista še posebej izpostavljeno.

V svojih sanjskih podobah Lipnik med drugim vidi tudi kosce, ki tečejo čez zeleno pobočje, kar ga znova vrne v otroštvo; spomni se, da mu je mati brala verze o Lojzetovi kosi, ${ }^{1}$ ki so nato v roman vključeni kot montaža in citati časopisnega izrezka.

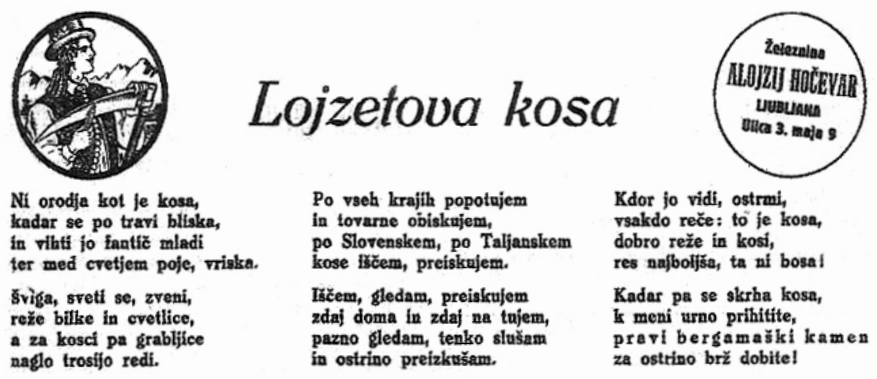

(Jančar 2008: 236).

Lipnikov beg v otroštvo, ki ga dosega z nenehnim prepletanjem spominov na besedila, ki mu jih je brala mati, mu poleg odmika od vsakdanjih tegob in težav v rutinskem zakonskem življenju, predstavlja zlasti vrnitev v čas, ko so mu bile odgovornosti in odločitve iz sveta odraslih še prihranjene. Vrnitev v čas mladosti mu pomeni nekakšno notranjo svobodo, ker pa tega »realno« ne more doseči, ga nezadovoljstvo s samim seboj peha iz ene v drugo izmišljijo.

\footnotetext{
${ }^{1}$ Izsek spada med stanovske kovaške pesmi, avtor ni naveden.
} 
Kratkotrajno potešitev mu nudi zgolj zatekanje v svet erotičnih memoarov in otroštva, kjer še enkrat »zagleda« svojo učiteljico Zalo. Ob tem se spomni pesmi Kovači smo, ${ }^{2}$ ki so se je učili v šoli.

Otroci zapojejo:

Kovači smo in naša sila

skovala nam bo sreče ključ

in iskra svetla izpod kladiva

prižgala bo svobode luč.

Sreče ključ, je rekla tovarišica Zala. (Jančar 2008: 239).

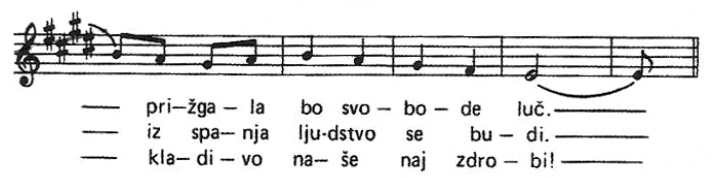

(Jančar 2008: 252).

Roman To noč sem jo videl sicer ne vsebuje nobenega primera montaže, vendar pa zato zajema tem bolj zanimiv primer izposoje osebe, ki priča o posebni samonanašalnosti oziroma avtoreferencialnosti. Izposojo uvrščamo med citatne figure prenosa besedilnega sveta, $\mathrm{tj}$. oseb, motivov ali dogajalnih prostorov, pri čemer se pisec zmeraj navezuje na en sam izvirnik, s katerim zaradi uporabe enakih elementov literarnega dogajanja vzpostavlja aluziven odnos (Juvan 2000: 271-274). Aluzija je namreč teže dojemljiv način medbesedilnega sklicevanja, saj največkrat obsega zgolj namig na kakšno znano besedilo, njena vsebinska raven pa ostaja zaradi posrednega delovanja pogosto nejasna. Poleg tega aluzija ni strukturno samostojna medbesedilna navezava, temveč se izraža skozi druge medbesedilne figure (Juvan 2000: 30-31).

Jančarjeva samonanašalnost se v romanu To noč sem jo videl kaže v izposoji lika Jozefa Erdmana, protagonista Severnega sija (1984), ki je v očeh drugih likov omenjenega romana viden takole:

»Moj prijatelj«, je rekel Samsa, »moj prijatelj Jozef Erdman, vrnil se je k nam, razuměs, $v$ svoje otroštvo.» /.../ »Tvrdka J. Śtastny in drug, specialna laboratorijska oprema«, je dodal Ondra. (Jančar 1993: 24)

Prenos Erdmanovega lika je v romanu To noč sem jo videl vključen v Stevanovo pripovedovanje o gostilniškem dogajanju, s čimer se vzpostavlja nova vzporednica med literarno referenco na Severni sij in njeno vključenostjo v zadnji Jančarjev roman:

${ }^{2}$ Besedilo je prva kitica prevoda ruske pesmi Filipa S. Škuleva iz časa po oktobrski revoluciji; slovenska varianta naj bi nastala med političnimi zaporniki v Sremski Mitrovici (Paternu 1995: 643). 
/.../ drugi je bil trgovski potnik, ki je ponujal laboratorijsko opremo. Ta je bil menda, če sem prav razumel, namenjen $v$ Trst in je tukaj čakal na prihod svojega sodelavca iz Prage, ime mu je bilo, ne vem, zakaj sem si to zapomnil, Erdman. (Jančar 2010: 52)

Čeprav omemba Erdmana v zgornjem navedku deluje nekoliko naključno, jo je mogoče razumeti veliko globlje; medbesedilna figura izposoje literarne osebe namreč s seboj prinaša vse svoje konotacije iz izvornega besedila, s čimer opozarja na tematsko-idejno sorodnost med obema romanoma. Erdmanov »konec« je bil posledica delovanja zgodovinskih silnic, zato je pričakovati, da bo usodni zasuk dogodkov v odločilni meri vplival tudi na Veronikino življenje. Četudi se pojavitev lika iz Severnega sija zdi bralcu nekoliko nenavadna, pa nedvomno zamaje njegov horizont pričakovanja, nakar se tekom pripovedi izkaže, da je bilo sklicevanje na omenjeni roman dokaj premišljeno, saj deluje kot namig bralcu, v okviru katerega tematsko-idejnega konteksta naj roman dojema. Oba protagonista namreč postaneta žrtvi nesrečnega spleta okoliščin, sproženih na ozadju druge svetovne vojne - zgodovina se tako še kar ne more odreči svojemu neprizanesljivemu poseganju v bivanjski položaj osrednjih protagonistov.

\subsection{Medbesedilna vloga metričnega citata v romanu To noč sem jo videl}

Metrični citat je medbesedilna figura posnetka jezikovnega izraza, ki obsega rabo verznega vzorca, oblikovno in funkcijsko drugačnega od metabesedila in siceršnjih poetičnih navad avtorja (Juvan 2000: 272). V romanu To noč sem jo videl se raba metričnega citata prepleta z elementi izrazne ter motivno-tematske reminiscence in aluzije, ko pesnik iz Ljubljane Veroniki pokloni svojo knjigo z naslovom Pesmi o zlatolaskah, pri čemer je opazno medbesedilno sklicevanje (metafikcijska digresija) na pesniško zbirko Pavla Golie, iz katere je v roman citatno vključena kitica pesmi Beživa! (»Beživa, v pijano se veselje potopiva, I da nama žal ne bo nekoč ... nekoč ... nekoč ... I In pesmi pojva lastno pot gredoč! / Kaj moreva, če je mladost minljiva! « Jančar 2010: 71), ki spominja na verzno ritmiko in tematiko Katulovega Blagoslova ljubezni (»Živiva, moja Lesbija, in se ljubiva /.../«).

V romanu citiran del Goljeve pesmi Beživa! tematizira uživanje v mladosti, življenju in ljubezni, s čimer aludira na začetek Katulovega Blagoslova ljubezni, le da ima nekoliko bolj odprt konec; namesto namigovanja na smrt se v pesmi Beživa! pojavi negotovost pred usodo in prihodnostjo, kar glede na zgodovinske okoliščine, $\mathrm{v}$ katere je romaneskno dogajanje postavljeno, sploh ni presenetljivo. Izzivajoče namigovanje na uživanje sedanjosti in, še posebej, mladosti pa obenem medbesedilno aludira na Veronikino prešuštvo - na njeno afero z jugoslovanskim oficirjem. Iz Goljeve pesniške zbirke sta nato v roman oziroma $\mathrm{v}$ pripovedovanje gospodinje citatno vpeti prva in druga kitica pesmi Ob uri mraka, ki uokvirja materino nestrpno pričakovanje Veronike, obenem pa s svojo motiviko namiguje na boleče zavedanje, da je pravzaprav ne bo nikoli več videla. Želja in »prazno« upanje se prav zaradi pronicanja občutij 
skozi Goljevo pesem zdita še večja, globlja in nevzdržno moreča, kar vnovič dokazuje pomensko večplastnost medbesedilnih navezav, ki omogočajo poglobljeno dojemanje romana.

\section{Sklep}

V Jančarjevih romanih Drevo brez imena (2008) in To noč sem jo videl (2010) so zastopane tako »tradicionalne« medbesedilne navezave (citati, moto, montaža ipd.) kot tiste, ki so se pričele opazneje pojavljati šele v zadnjih desetletjih (metafikcijska digresija, reminiscenca, izposoja ipd.) Medbesedilni sklici, zastopani v romanu Drevo brez imena, imajo osrednjo funkcijo pri vzpostavljanju (posteksistencialistične) idejno-tematske podlage, na katero opozori že moto, dokončno pa jo razvijejo citati ljudskega pripovedništva in z njimi povezane aluzije, reminiscence in montaže. Ti obenem opozarjajo na Jančarjevo sledenje tematski paradigmi, ki zaznamuje skoraj celoten pisateljev prozni opus in izhaja iz eksistencialne odvisnosti likov od usodnega in neprizanesljivega zgodovinskega dogajanja.

Obema romanoma je torej skupna omenjena (post)eksistencialistična duhovnozgodovinska podlaga, le da jo v romanu To noč sem jo videl poleg mota soustvarjajo še izposoja lika Jozefa Erdmana, dobesedni in metrični citat(i) ter aluzije in reminiscence. V nasprotju z Drevesom brez imena so v zadnjem Jančarjevem romanu citati ljudskega slovstva zaslužni predvsem za vzpostavitev karakterne ravni osrednje protagonistke, ki jo - na trenutke sicer precej samosvojo intelektualko - bralcu približajo kot ljubiteljico slovenskih narodnih pesmi, kar jo napravi še posebej domačo in prikupno. Z upoštevanjem medbesedilnih navezav se torej v obravnavanih Jančarjevih romanih ne samo poglablja in širi njuna idejno-pomenska vrednost, temveč se vzpostavlja mreža medbesedilnih sklicev, predlog in njihovih konotacij, kar omogoča številna interpretacijska izhodišča.

\section{VIRI IN LITERATURA}

Anton AŠKERC, 1946: Balade in romance lirske in epske poezije. Ljubljana: Državna založba Slovenije. (Zbrano delo; 1. knjiga).

Franček BOHANEC, ur., 1972: Ljudske pripovedi. Ljubljana: Mladinska knjiga. (Izbrano delo.)

Silvija BOROVNIK, 2001: Pripovedna proza. Slovenska književnost III. Jože Pogačnik idr. Ljubljana: Državna založba Slovenije. 147-201.

Marjetka GOLEŽ KAUČIČ, 2007: Ljudsko pesemsko izročilo kot kulturni spomin Jančarjevega romana in drame Katarina, pav in jezuit. Traditiones 36/2. 77-113.

Pavel GOLIA, 1921: Pesmi o zlatolaskah. Ljubljana: Slovenska Matica. 
Drago JANČAR, 1993: Severni sij. Celovec: Založba Wieser.

- -, 2008: Drevo brez imena. Ljubljana: Modrijan.

- -, 2010: To noč sem jo videl. Ljubljana: Modrijan.

Marko JUVAN, 1987: Dialog literature z literaturo ali kaj so literarne reference. Problemi - Literatura 25/1. 99-111.

- -, 1991/92: Uvod v medbesedilno branje (pesmi). Jezik in slovstvo 37/3-4. 53-61.

- -, 2000: Intertekstualnost. Ljubljana: Državna založba Slovenije. (Literarni leksikon 45.)

- -, 2000a: Vezi besedila. Ljubljana: Literarno-umetniško društvo Literatura.

- -, 2006: Literarna veda v rekonstrukciji: uvod v sodobni študij literature. Ljubljana:

Literarno-umetniško društvo Literatura.

Edvard KOCBEK, 1963: Groza. Ljubljana: Slovenska matica.

Janko KOS, 2001: Primerjalna zgodovina slovenske literature. Ljubljana: Mladinska knjiga.

Katarina MARINČIČ, 2008: Sočutje in veščina. Drago Jančar: Drevo brez imena. Ljubljana: Modrijan. 279-285.

Boris PATERNU (ur.), 1995: Slovensko pesništvo upora 1941-1945. Ljubljana: Filozofska fakulteta. (2. knjiga).

Martina POTISK, 2011: Medbesedilnost v romanih Draga Jančarja. Maribor: diplomsko delo.

France PREŠEREN, 1975: Poezije. Ljubljana: Cankarjeva založba.

Marija STANONIK, 1999: Slovenska slovstvena folklora. Ljubljana: Državna založba Slovenije.

--, 2001: Teoretični oris slovstvene folklore. Ljubljana: Založba ZRC, ZRC SAZU.

- -, 2003: Funkcija slovstvene folklore v sodobnem slovenskem romanu. Sodobni slovenski roman. Ur. Miran Hladnik in Gregor Kocijan. Ljubljana: Filozofska fakulteta (Obdobja, 21). 333-341.

- -, 2006: Procesualnost slovstvene folklore: slovenska nesnovna kulturna dediščina. Ljubljana: Založba ZRC, ZRC SAZU.

Sveto pismo stare in nove zaveze, 1994. Ljubljana: Svetopisemska družba Slovenije.

Marko TERSEGLAV, 1987: Ljudsko pesništvo. Ljubljana: Državna založba Slovenije. (Literarni leksikon 32).

Tomo VIRK, 1997: Tekst in kontekst: Eseji o sodobni slovenski prozi. Ljubljana: Literarno-umetniško društvo Literatura.

- -, 1998: Premisleki o sodobni slovenski prozi. Ljubljana: Zavod Republike Slovenije za šolstvo.

- -, 2000: Strah pred naivnostjo. Ljubljana: Literarno-umetniško društvo Literatura.

Franc ZADRAVEC, 2002: Slovenski roman 20. stoletja. Drugi analitični del in nekaj sintez. Murska Sobota: Pomurska založba. 


\section{THE INTERTEXTUAL ASPECT OF THE NOVELS BY DRAGO JANCAR THE NAMELESS TREE AND I SAW HER THAT NIGHT}

The main purpose of the article is to expose the role and function of the selected intertextual figures and genres in the two novels by Drago Jančar Drevo brez imena (The Nameless Tree, 2008) and To noč sem jo videl (I Saw Her That Night, 2010). Through the introductory passages Drago Jančar as one of the most remarkable representatives of the Slovenian literary post-modern era is presented. His literary work includes nine novels, most of them based on (post)existentialistic spiritual-historic and philosophical tendencies. Moreover, the paper shows some of the intertextual references in Jančar's novels and highlights their relations to the textual context. Special attention is given to the most visible references, e.g. motto, montage, borrowing, metric quote, quotation and allusion, in the two previously mentioned author's novels. The significant intertextual references in the novel The Nameless Tree are the prefaced motto, which includes Kohelet's quotation, citing of the folk narrative and various examples of the montage. These intertextual elements are important contributors to the maintaining of the novel's idea and theme. They pointed out the alienation of the protagonist and his inability to cope with problems that consequently leads to his incessantly escapes from the real life into imaginary world, attained by reading archival documents and remembrance of his childhood associated with the background of World War II. The novel I Saw Her That Night undoubtedly has some poetical similarities with Jančar's previous novel; its intertextual aspect proves that the figure of motto, which includes Andersen's quotation, and the borrowing of Jozef Erdman from the writer's novel Severni sij (Northern Lights, 1984) lead to the understanding of the fatal historical circumstances that have a huge impact on the characters' lives. On the contrary, I Saw Her That Night contains many quotations, combined with allusions, of the folk poetry and other templates that bring protagonist near to the reader by stressing her nature and the ways of thinking or feeling. Therefore the intertextual references in both of the novels help to create and strengthen different receptive levels and provoke many interpretative starting points. 